\title{
Rethinking How We Teach and Assess Reading Comprehension
}

\author{
Hugh W. Catts \\ Florida State University
}

In Press

American Educator 
It is February 2015, and I am at a national conference listening to a panel present the results of their research on improving reading comprehension. Several members of the panel, like myself and a few others in the room, are funded by the Institute of Education Sciences as part of the Reading for Understanding Initiative. This \$120 million program supported six interconnected research teams in their efforts to improve reading achievement in the US. ${ }^{1}$ Educators and policy makers had for some time been concerned about the performance of American children on tests of reading achievement. Over the last 20 years, only about a third of students have scored at the proficient level on the reading subtest of the National Assessment of Educational Progress (NAEP). ${ }^{2}$ This assessment is administered biannually to a representative sample of fourth- and eighth-grade students (and every four years to twelfth graders) from across nation. Somewhat better, though still troubling, levels of performance have also been reported on state-based reading tests, administered annually starting in third grade. The Reading for Understanding Initiative was intended to jump start instruction in reading comprehension and significantly improve reading achievement on state and national assessments. In fact, it was described by program officials as the "moonshot" for reading comprehension.

Unfortunately, the preliminary results that the panel presented fell short of these expectations. The reported studies found that students receiving a variety of comprehension interventions made gains, compared with control groups, on assessments closely tied to the interventions - but they showed limited or no significant gains on standardized measures of reading comprehension. Needless to say, conference attendees were surprised and discouraged by these results.

Sitting in the back of the room, I clearly remember not being particularly alarmed by what the panel reported. As part of my work on the Reading for Understanding Initiative and 
earlier related projects, I had spent many hours thinking, studying, and talking with teachers and colleagues about reading comprehension. Through these efforts, I had come to recognize that the field's general approach to reading comprehension was short-sighted. We were treating reading comprehension as if it were a single construct that could be measured with one or more general reading tests and improved with a short-term intervention. At a deeper conceptual level, most researchers (including those funded by the Reading for Understanding Initiative), recognized that reading comprehension was multidimensional, but it had been common practice in education and research for some time to study, assess, and provide instruction as if comprehension were a skill, rather like swimming. If we teach someone to swim, they can soon transfer that skill to any body of water whether it be a pool, lake, or ocean. But reading comprehension is not a skill someone learns and can then apply in different reading contexts. It is one of the most complex activities that we engage in on a regular basis and our ability to comprehend is dependent upon a wide range of knowledge and skills.

\section{The Comprehension as Skill Myth}

How have we come to think of comprehension as a skill? I believe a major reason this has occurred is because we have talked and written about comprehension in the context of related skill-like abilities. Discussions about reading often include the topics of phonics, fluency, and related skills, such as phonemic awareness, together with comprehension. As an example, take the work of the National Reading Panel. ${ }^{3}$ This panel of reading experts was convened by Congress to assess the effectiveness of different approaches to teaching reading. They examined a wide range of instructional approaches related to comprehension but in overviews of their work, comprehension has been reduced to one of the "Big Five," along with phonemic 
awareness, phonics, fluency, and vocabulary. As such, it is depicted alongside these skills as one of the "pillars" of reading. In another common graphic, the word comprehension is displayed within a box similar in design (actually smaller) to boxes for other skill-like components of reading. Whereas such a consideration and depiction are thought to form a useful heuristic, it can give the false impression that comprehension is comparable to these skills in terms of its complexity and the way it is best taught and measured.

Furthermore, widely used approaches to teaching reading comprehension reinforce this view. ${ }^{4}$ Comprehension has typically been taught through the use of strategies such as "find the main idea," "make a prediction," or "monitor your comprehension." These strategies are taught and practiced in order to gain automaticity much like what is done with other skill-like behaviors. This, in turn, can lead us to believe that comprehension can be thought of in a similar manner to these other skills.

\section{A More Accurate and Complex Model}

Despite this common view about comprehension, several lines of research have recognized the true complexity of reading comprehension for some time. Nearly 20 years ago this complexity was captured by the RAND Reading Study Group. ${ }^{5}$ This federally funded group was charged with developing a research agenda to address pressing issues in literacy. As part of their report, they conceptualized reading comprehension as a combination of factors within three different categories: the reader, the text, and the activity of reading.

The reader brings a set of cognitive abilities (such as attention, memory, and reasoning), language knowledge and skills, motivations and interests, and background knowledge to the task of reading. Readers vary considerably in these factors and this variability impacts their 
comprehension. Considerable research attention has been focused on reader variables and their impact on comprehension are well documented.

The text includes such elements as genre, topic, and complexity. Students encounter texts with different genres — such as narrative, descriptive, expository, or persuasive — and these texts vary in their subject matter and level of complexity. Although not emphasized in the RAND report from 2002, texts also now vary in their form. They may be in a paper or digital form and the latter can be displayed on a variety of devices, such as the phone, tablet, or computer. Each of these forms imposes its own set of constraints and challenges on comprehension. The notion of multiple texts can also be added to this category to account for the fact that skilled readers often rely on more than one text for comprehension.

The activity refers to the task or purpose of reading. It is often argued that the purpose of reading is comprehension. But we actually seek to comprehend for a specific reason, be it to prepare for a test, evaluate the strengths of an argument, learn the rules of a game, or enjoy a magazine article or book. Each purpose brings unique knowledge and skills that must be acquired to be successful.

Importantly, the RAND Reading Study Group viewed these various elements interacting within a socio-cultural context that involves factors such as where the reading occurs (e.g., school or home), how much support there is (e.g., individual, teacher- or caregiver-led, or group activity), and what cultural value is placed on reading by students' families, peers, racial and ethnic groups, and other groups that are central to the students' identities.

Taken together, it is easy to see how any one individual may have multiple levels of comprehension ability depending upon what they are reading and why they are reading it. As a result, comprehension cannot be reduced to a single notion because it is not a single ability. 


\section{The Role of Knowledge}

Chief among the factors influencing reading comprehension is background knowledge. Research clearly shows that how much readers understand about the text's topic before they read it is a major factor in how much they understand while and after they read it. ${ }^{6}$ Unfortunately, much of the efforts directed toward improving reading comprehension have neglected building background knowledge. (As discussed later, there are widely used strategies for "activating" background knowledge, but they do not necessarily develop new knowledge.) It was this neglect that first alerted me to the problems with the way we were thinking about reading comprehension.

In my graduate training, many years ago, I was introduced to the role of knowledge in reading comprehension. At that time, schema theory was a popular topic in research on human cognition and learning. A schema is an organized unit of knowledge that forms the foundation for many activities involving human thought. Richard Anderson, a professor of educational psychology, brought the notion of a schema to education and argued for its critical role in reading comprehension as well as learning in general. ${ }^{7} \mathrm{He}$ was among the first to convey to me the importance of teaching knowledge to improve comprehension.

In my psychology classes, I was introduced to a study that continues to be one of my favorites. The following passage, which was designed to be ambiguous, was read aloud to college students, and they were asked to recall as much as they could. ${ }^{8}$

The procedure is actually quite simple. First you arrange things into different groups. Of course, one pile may be sufficient depending on how much there is to do. If you have to go somewhere else due to lack of facilities that is the next step, 
otherwise you are pretty well set. It is important not to overdo things. That is, it is better to do too few things at once than too many. In the short run this may not seem important but complications can easily arise. A mistake can be expensive as well. At first the whole procedure will seem complicated. Soon, however, it will become just another facet of life. It is difficult to foresee any end to the necessity for this task in the immediate future, but then one never can tell. After the procedure is completed one arranges the materials into different groups again. Then they can be put into their appropriate places. Eventually they will be used once more and the whole cycle will then have to be repeated. However, that is part of life.

Students given the topic of the passage beforehand quickly made sense of what they heard and recalled many details. (Those students were told, “The paragraph you will hear will be about washing clothes.") But those who heard the same passage without the topic were confused and recalled little. Of particular interest, a third group of students was given the topic after they heard the passage, but they too were confused and recalled little. Of course, it was not simply the topic but rather the knowledge associated with it that allowed the students to make sense of what they had heard - but only if this knowledge was available from the start.

It was studies like this, including similar ones involving reading rather than listening, that early on clearly demonstrated for me the importance of knowledge for comprehension. But somewhere along the line, educators and researchers — myself included — got distracted and failed to pay attention to its importance. It is not exactly clear how this happened. Perhaps it was a shift in focus to bottom-up models of reading that argued that meaning was contained within the text and the reader's job was to extract it. Or maybe it was just that knowledge took too much 
time to teach and it made more sense to focus on skills that could be taught quickly and applied across topics. Also, considering comprehension alongside skill-like aspects of reading probably distracted us from the role of knowledge.

But whatever the reason, knowledge has come back to the forefront in discussions of reading comprehension. Proponents such as E. D. Hirsch, Daniel Willingham, and Natalie Wexler have written extensively about the role of knowledge in comprehension. ${ }^{\text {a }}$ Their work and that of others ${ }^{9}$ has begun to have an influence on research in reading comprehension, but change has been slow. Some of the projects in the Reading for Understanding Initiative did have knowledge as a central component but the other projects paid only limited attention to knowledge in instruction and/or assessment. Limited attention also plagued other large-scale projects such as those within the Striving Reader program. This program funded by the Department of Education involved a set of 17 studies designed to improve reading comprehension in middle and high school students. ${ }^{10}$ While materials did address different topics, there was no direct effort to build knowledge as part of the intervention or assessment. Again, it is not surprising that these studies only demonstrated small effects at best on improving reading comprehension.

\section{What Knowledge Does for Comprehension}

Why is knowledge so critical for comprehension? To begin with, it provides a framework for organizing incoming information and guides us as we read through a text. We better understand what the topic is and have expectations about where a passage may be going. By doing so,

\footnotetext{
${ }^{\text {a}}$ For articles by Hirsch, Willingham, and Wexler on the importance of building knowledge, see the reading section of American Educator's subject index: aft.org/ae/subject-index. [Luke is adding this to the reading section: aft.org/periodical/american-educator/spring-2006/how-knowledge-helps]
} 
knowledge keeps us on track and prevents us from going down "blind alleys" in our understanding. This framework also gives us a place to anchor new information in memory and associate it with past knowledge. We use these building blocks of the new and the old to construct an initial understanding of what we are reading and then continuously revise and add to it as we move through a text. It is this integration of the new information in the text with what we already know that brings meaning to what we read.

Background knowledge also allows us to make inferences and fill in information that is not explicitly provided. Authors rarely tell us all we need to know in order to understand a text, so we need to fill in some of the details with our background knowledge. Knowledge also enables us to more easily recognize which of the multiple meanings of a word is appropriate for the context. For example, when reading a passage about baseball, knowing that the word pitcher refers to a person rather than an object could be critical for comprehension.

Knowledge is also essential for thinking. But in certain contexts these days it is seen as secondary to thinking. Critical thinking has become the rage in education. All too often, teachers are urged to engage students in thinking deeply and critically about what they read as if these skills were independent of the topic; meanwhile, background knowledge is downplayed as if the specific information about a topic could be looked up on the internet when necessary. ${ }^{11}$ But it is the specific information that gives students something to think critically about—and our minds are surprisingly limited in how much new information they can take in at one time. Knowledge must accumulate over time to assure a level of depth that allows for a critical analysis of the subject matter. We can't think logically about different approaches to government without knowing a lot about different forms of government. So, in this sense, knowledge is the most critical component of critical thinking. 
Knowledge also allows us to make the most use of our working memory, where much of thinking takes place. There are limitations on how much information we can hold and think about simultaneously in working memory and this amount is heavily influenced by knowledge. Knowledge coming from long-term memory places a much smaller burden on working memory than new knowledge coming from a text (or a speaker); it also leaves us with more capacity in working memory to think about things in novel ways. As a simple example, it is easier to remember the letter sequences USA, FBI, and NBC than PDQ, RJB, and FVO. When reading, the more information related to the topic we already have stored in long-term memory, the more deeply we can think about that topic — even as we read a passage that offers new information.

Finally, the relationship between knowledge and reading comprehension is reciprocal in nature. Not only does knowledge improve comprehension but comprehension allows the reader to build new knowledge. Creating a coherent understanding of what one reads modifies background knowledge that is available for subsequent reading comprehension either later in the same text or in future reading of related texts. ${ }^{12}$

\section{Implications for Instruction}

It should be evident from my comments that improving reading comprehension is a complex process that requires multiple levels of instruction and practice. Clearly, building background knowledge that is both deep and broad is needed to lay the foundation for comprehension and for further knowledge acquisition. However, students also need high quality reading instruction involving decoding, fluency, vocabulary, and comprehension strategies in order to best use their knowledge in different reading contexts and for different purposes. 
For many years, the primary way knowledge has been addressed in the context of reading has been through activating background knowledge using strategies like prereading discussions, concept maps, and anticipation guides. These strategies can be effective— but they only work when the appropriate knowledge is available. Often children will not have the requisite knowledge, or their knowledge will be impoverished or inaccurate. If inaccurate, this activation can actually be detrimental to comprehension.

Whereas knowledge activation has been widely viewed as a component of reading instruction, building knowledge often has not. In fact, instruction devoted to content knowledge has actually been replaced by other aspects of reading instruction. In most elementary schools, social studies and science instruction has been supplanted by English language arts (ELA) instruction. Surveys have shown that, on average, children in grades 1-4 receive only 2.3 hours of science instruction per week, whereas four times that amount is spent on ELA instruction teaching word reading skills, comprehension strategies, and vocabulary. ${ }^{13}$ The thinking has been that if we want children to improve their reading comprehension, we have to work on reading skills to achieve fluency before we can use reading to build knowledge. However, this false dichotomy between learning to read and reading to learn has not led to better reading achievement.

Recently, educators have begun to rethink reading instruction and consider how to better integrate knowledge acquisition with literacy in ELA instruction. ${ }^{14}$ In these more integrated approaches, students build knowledge at the same time they are learning reading-related skills. This involves a concentrated effort to build rich and connected ideas about social studies, science, and other subjects during ELA lessons. Such instruction does not necessarily replace the science and social studies instruction that may be taking place at other times but rather 
supplements it. As with other content instruction, reading materials in an integrated ELA program are selected to build knowledge. Instead of reading about volcanoes one day and Rosa Parks the next, which has often been the case in ELA instruction, reading materials are arranged by topic in a logical and sequential manner and form an integrated content-rich curriculum. In this way, knowledge is acquired and accumulated over time.

Such content-rich, connected instruction can be especially engaging and can draw children's interests to literacy and learning. Student engagement and learning can be further fostered by culturally responsive instruction. One example is a program called Readiness through Integrative Science and Engineering. ${ }^{15}$ This program takes a home-to-school approach to connect new knowledge with culturally relevant knowledge concerning the people, places, and objects that students interact with on a daily basis. By understanding, appreciating, and connecting with this knowledge, learning can be especially enhanced for all children.

In an integrated literacy and knowledge-building curriculum there should be a strong focus on teaching fundamental reading skills. Depending on the grade and specific skills taught, instruction in decoding, spelling, and fluency could comprise its own unit or be blended with discussion and activities designed to acquire and build content-area knowledge. Vocabulary, an important focus of ELA instruction, can be taught especially well within a content-rich integrated curriculum. Novel words related to the content are excellent targets for instruction. These words are often repeated multiple times in a text and their meanings are well supported by the context in which they occur. In addition, once learned they become part of the knowledge base of the topic. General purpose academic words, or what are sometimes referred to as Tier 2 words, also are learned more easily in a rich context. When these words are supported by content knowledge, 
the reader can use this knowledge to more easily infer their meaning. Also, a rich context can prove particularly helpful in learning words with multiple meanings such as "bright" or "palm."16 Content-rich materials are also excellent contexts in which to learn more about academic language. Written language is characterized by more complex grammar than spoken language, and students can benefit from explicit instruction in how this grammar works. Specifically, science texts tend to privilege nouns for compacting information, developing logical reasoning and achieving precision. ${ }^{17}$ For example, consider this text: "asthma is a disorder in which the respiratory passages narrow significantly as a result of an allergen. This narrowing...." Here the author creates an abstract noun (i.e., this narrowing) to represent the entire previous clause. Recognizing the referent of this abstract noun is critical to comprehension and, in cases like this, could benefit from explicit instruction. In other academic texts, students will be confronted with complex and elaborated noun phrases rather than reduced ones. For example, take the following sentence, which is modified slightly from a social studies text. "The stories that were told to them by explorers and missionaries, just back from their long track West, were filled with images of vast, open landscapes, abundant game and pristine rivers and lakes." Given the complexity of such noun phrases, explicit instruction in how to unpack noun phrases and identify the head noun(s) could prove helpful to students in understanding academic texts.

Integrated approaches also can incorporate many of the same comprehension strategies employed in traditional ELA instruction. Some of these strategies, like inferencing and paraphrasing, are rather general and can be explicitly taught and used across various contexts. However, within an integrated approach, some strategies are best selected and taught based on their relevance to what is being read and for what purpose. The nature of texts and purposes for 
reading vary across subject matters, and thus, the strategies that may be most advantageous will vary as well.

Some of these strategies will be the common ones (e.g., mental imagery) identified by the National Reading Panel. Others will be more text- and task-specific metacognitive approaches to assist comprehension. For example, during a social studies lesson, students may be presented with an explanation or argument and asked to evaluate its validity. In such a case, students would benefit from explicit instruction and practice on how to identify a claim and judge the relevance, sufficiency, and accuracy of the evidence provided. Alternatively, science texts often provide a description of some object, animal, or process and students reading passages from such a text are often tested on what they have learned. For such a task, students may benefit from being taught how to use a graphic organizer to summarize and categorize the information within different organizational structures. Students will also benefit from recognizing that a science text (from a trustworthy source) is an authoritative account and is different from texts in which the author's perspective is central, such as a poem or a historical figure's diary entry. This more nuanced approach to strategies becomes ever more important as students move through the grades and the comprehension skills needed are increasingly determined by the characteristics of the text and the activities carried out within the different disciplines. Nevertheless, knowledge of how disciplinary texts work or what is called disciplinary literacy can and should be part of instruction in the elementary grades. ${ }^{18}$

There are now quite a few integrated, content-rich curricula being used across the country. Some of these programs are commercially available through curriculum publishers, such as Core Knowledge Language Arts and Wit \& Wisdom, whereas others have been developed by researchers, for example, Model of Reading Engagement. ${ }^{19}$ Some of these 
programs have been developed specifically to be used as part of ELA instruction. Others are truly integrated across the curriculum and operate instead of or in addition to ELA materials. There is also quite a bit of variability in the scope of literacy instruction within these programs. Nevertheless, a recent meta-analysis showed that when compared with traditional programs in which literacy and content instruction were provided separately, integrated content-rich programs resulted in students scoring significantly better on vocabulary and comprehension (including on standardized measures of comprehension). Not surprisingly, significant gains were also made in content taught. ${ }^{20}$

\section{Implications for Assessment}

The multidimensional nature of reading comprehension presents a significant challenge for assessment. Because of the numerous factors in play, comprehension ability is more fluid than often thought. In other words, any one individual will have different levels of ability depending on what is read and for what purpose.

Perhaps the best demonstration of this variability and its impact on assessment comes from a study that included scores from 995 children who were administered four different standardized measures of reading comprehension. ${ }^{21}$ The researchers found that the median correlation between the different tests was only .54, which was surprisingly low given that the tests purported to measure the same thing. In another analysis of the data, they identified children scoring in the lowest $10^{\text {th }}$ percentile on each of the measures and compared the overlap of these groups across measures. Their results showed that, on average, only $43 \%$ of the children identified by one test as poor readers were also identified as poor readers on another test. In other words, the odds of any two tests diagnosing the same student as having a comprehension deficit 
were less than half. Further analyses showed that it was not just a problem of consistency at the lower end of the scale; there was just as much inconsistency in identifying children performing in the highest $10^{\text {th }}$ percentile.

The inconsistency in the results of the different measures of reading comprehension were likely due in part to the poor reliability of these measures, something that is not uncommon for diagnostic measures of reading comprehension. One the other hand, the measures also differed in their formats, so that could have contributed to the variability. One measure employed a cloze task in which children read passages and filled in missing words. In the others, children read either passages or single sentences and then answered open-ended or multiple-choice questions. These formats are known to place different demands on reading-related processes such as word reading, language ability, and working memory. ${ }^{22}$ Thus, children with different strengths and weaknesses in these processes would be expected to perform differently on the measures.

The content of the passages/sentences may also have added to the variability of the measures. That is, children were likely to have varied in their knowledge about the topics covered and that could have influenced their performance. Such variability may be present not only across tests but also across passages within a test. For example, in the Reading for Understanding project that my colleagues and I carried out, students read four different passages from an informal reading inventory and answered open-ended questions. We observed considerable variability within students from one passage to another. It was not uncommon for a student to get nearly all the questions correct on one passage and most wrong on another. Whereas there may be several reasons for this variability, differences in background knowledge is a likely contributor. 
Because of the variability due to passages, state- and national-level tests of reading use numerous passages that cover multiple topics. But, of course, this introduces the problem of these tests favoring students who have more knowledge about a broad range of topics than those with less knowledge. This has led E. D. Hirsch to argue that reading tests are actually knowledge tests in disguise. ${ }^{23}$

The fact that state and national reading tests are knowledge heavy introduces a further problem. That is, performance on these tests will likely be more difficult to change in the short term since knowledge acquisition is incremental in nature. Indeed, as I stated at the outset, American children's performance on the NAEP has remained virtually unchanged for some time. This has been in spite of significant federal, state, and local efforts. For example, in North Carolina, the percentage of students failing to reach proficiency on state reading tests has remained largely unchanged, hovering above 50 percent, since 2013-14, when the state passed its K-3 Read to Achieve literacy act. ${ }^{24}$

Maybe the problem is not only the instructional practices teachers have been encouraged to use but also the way we are assessing comprehension. An alternative approach would be to teach children using an integrated literacy and content-rich curriculum and to test their ability to read and comprehend passages covered in that curriculum. In other words, offer a better match between instruction and assessment. Don't just test the skills and strategies that have been taught; test the specific content-area topics that have been taught. Such an approach would be fairer and more equitable for all involved. Teachers would have a clear idea of what content within which to imbed their literacy instruction. Students would have the opportunity to learn from content-rich curricula and be assessed based on what they learned in school (instead of what they may or may not have learned at home, over the summer, etc.). Also, because 
instruction would be better matched with assessment, there would be a greater opportunity for schools and districts to evaluate the progress they are making.

One approach that has attempted to better match instruction with assessment is being carried out within the guidelines of the Every Student Succeeds Act assessment pilot program. ${ }^{25}$ This program encourages local involvement in the development of the next generation of assessments. It allows states, with approval by the US Department of Education, to pilot new and innovative assessments in lieu of current state exams. Initially, this takes place in a small number of districts before moving on to statewide implementation. To date, five states have received approval to develop these assessments. Most notable, Louisiana has begun a multi-year process to offer a humanities assessment as an alternative to its English language arts and social studies assessments. ${ }^{26}$ The new humanities assessment draws from texts and topics that are included in the state's recommended curriculum. ${ }^{27}$ Importantly, teachers across the state were involved in the curriculum development and evaluation process, resulting in high buy-in. Thus, the content of the test will be well matched with the instruction students receive.

A very limited pilot of this new assessment, LEAP 2025 Humanities, began in the 201819 school year and then implementation was interrupted by the pandemic, ${ }^{28}$ so it will likely be several more years before researchers can evaluate the impact of this new approach. Of course, designing an assessment that is in keeping with current research on literacy development is just the first step. The extent to which the assessment will help enhance instructional practices depends on many related components, including professional development on how to use the results to inform teaching, time for teachers to learn collaboratively as they adjust to the new assessment, and the stakes tied to the assessment results. In fact, one of the findings of the Reading for Understanding Initiative was that "a major roadblock to teacher uptake of new 
practices is the accountability infrastructure of reform movements. The more test scores matter, the less the likelihood that teachers will adopt novel teaching practices."29

Still, I am especially encouraged by Louisiana's efforts and am hopeful that other states and districts will also consider how to better align what is tested with what is taught. It is these types of programs combined with integrated literacy and content-rich curricula that I believe can better address comprehension. These programs move beyond characterizing comprehension as simply one of the "Big Five" and recognize its complexity and what it will take to help all children understand and learn from what they read. I look forward to attending future conferences where the results of these programs are presented.

\section{Endnotes}

\footnotetext{
${ }^{1}$ https://naeducation.org/reaping-the-rewards-of-reading-for-understanding-initiative/

${ }^{2}$ https://www.nationsreportcard.gov/reading/nation/achievement/?grade $=4$

${ }^{3}$ National Reading Panel, "Report of the National Reading Panel--Teaching Children to Read: An Evidence-Based Assessment of the Scientific Research Literature on Reading and Its Implications for Reading Instruction," (2002, Washington, D.C.: National Institute of Child Health and Human Development).

${ }^{4}$ danielwillingham.com/uploads/5/0/0/7/5007325/willingham\&lovette_2014_can_reading_comprehension_be_ta ught_.pdf

${ }^{5}$ Snow, "Reading for understanding: Toward an R \& D program in reading comprehension," (2002, Santa Monica, CA: RAND). rand.org/pubs/monograph reports/MR1465.html

${ }^{6}$ G. N. Cervetti and T. S. Wright, "The role of knowledge in understanding and learning from text." In Handbook of Reading Research, ed. E.B. Moje, P. Afflerbach, P. Enciso, and N. K. Leseaux (Taylor and Frances Group, 2020).

${ }^{7}$ R. Anderson, "Schema-Directed Processes in Language Comprehension." In Cognitive Psychology and Instruction, ed. A. M. Lesgold, J. W. Pellegrino, S. D. Fokkema, and R. Glaser, (New York: Plenum, 1978).

${ }^{8} \mathrm{~J}$. Bransford and M. Johnson, "Contextual prerequisites for understanding: Some investigation of comprehension and recall." Journal of Verbal Learning and Verbal Behavior, 11 (1972): 717-726, quote from page 722.

${ }^{9}$ For a review written by one of these pioneers, who in turn describes several others, see https://www.researchgate.net/publication/230531493 The Role of Knowledge in Early Literacy.

${ }^{10}$ https://ies.ed.gov/ncee/pubs/20164001/pdf/20164001.pdf

${ }^{11}$ For a paper that addresses many of the widespread misconceptions about critical thinking, see http://www.danielwillingham.com/uploads/5/0/0/7/5007325/willingham 2019 nsw critical thinking2.pdf.

${ }^{12}$ https://naeducation.org/reaping-the-rewards-of-reading-for-understanding-initiative/

${ }^{13}$ R. K. Blank, "What is the impact of decline in science instructional time in elementary school? Time for elementary instruction has declined, and less time for science is correlated with lower scores on NAEP," (2012, Palo Alto, CA: Noyce Foundation). Retrieved from http://www.csss-science.org/downloads/NAEPElemScienceData.pdf
} 
${ }^{14}$ See, for example, the Knowledge Matters Campaign, knowledgematterscampaign.org, and Curriculum Matters, curriculummatters.org.

${ }^{15}$ C. M. McWayne, J. Mistry, S. Hyun, V. Diez, C. Parker, et al., "Incorporating knowledge from children's homes and communities," Young Children, 75 (2020): 20-26.

${ }^{16} \mathrm{https}$ ///achievethecore.org/aligned/robust-vocabulary-instruction/

${ }^{17}$ Z. Fang, "Scientific literacy: A systematic functional linguistics perspective," Science Education, 89, 2005: 335347.

${ }^{18} \mathrm{C}$. Shanahan and T. Shanahan, "Does disciplinary literacy have a place in elementary school?" The Reading Teacher, 67, 2014: 636-639.

${ }^{19}$ J. S. Kim, M. A. Burkhauser, L. M. Mesite, C. A. Asher, J. E. Relyea, J. Elmore, .... J. E. Relyea, "Improving reading comprehension, science domain knowledge, and reading engagement through a first-grade content literacy intervention," Journal of Educational Psychology, 2020, Advance online publication.

${ }^{20} \mathrm{H}$. Hwang, S. Q. Cabell, and R. Joyner, "Two are better than one? A meta-analysis of the impact of integrated instruction on comprehension and vocabulary in the elementary years. Manuscript under review."

${ }^{21} \mathrm{~J}$. Keenan and C. Meenan, "Test differences in diagnosing reading comprehension deficits," Journal of Learning Disabilities, 47, (2014):125-135.

$22 \mathrm{~J}$. Keenan, R. Betjemann and R. Olson, "Reading comprehension tests vary in the skills they assess: Differential dependence on decoding and oral language," Scientific Studies in Reading, 12, (2008): 281-300.

${ }^{23}$ E.D. Hirsch. Why knowledge matters: Rescuing our children from failed educational theories, (Cambridge, MA: Harvard Education Press, 2016).

${ }^{24}$ S. Koon, B. Foorman, and T. Galloway, "Identifying North Carolina students at risk of scoring below proficient in reading at the end of grade 3" (2020 Washington, DC: U.S. Department of Education, Institute of Education Sciences, National Center for Education Evaluation and Regional Assistance, Regional Educational Laboratory Southeast), Retrieved from http://ies.ed.gov/ncee/edlabs

${ }^{25}$ Every Student Succeeds Act of 2015, Pub. L. No. 114-95, 129 Stat. 1802 (2015).

${ }^{26}$ For the state's documents on the assessment, visit louisianabelieves.com/resources/library/assessment, and scroll down to the section titled "LEAP 2025 Humanities."

${ }^{27}$ https://www.louisianabelieves.com/docs/default-source/assessment/national-update-on-la's-innovativeassessment-pilot.pdf

${ }^{28} \mathrm{https}$ ://www.louisianabelieves.com/docs/default-source/assessment/parent-guide-to-leap-2025-humanities.pdf and http://edreformnow.org/wp-content/uploads/2020/11/Louisiana-IADA-LEAP-2025-Humanities.pdf

${ }^{29} \mathrm{https}$ ://naeducation.org/reaping-the-rewards-of-reading-for-understanding-initiative/; quote from p. 5 


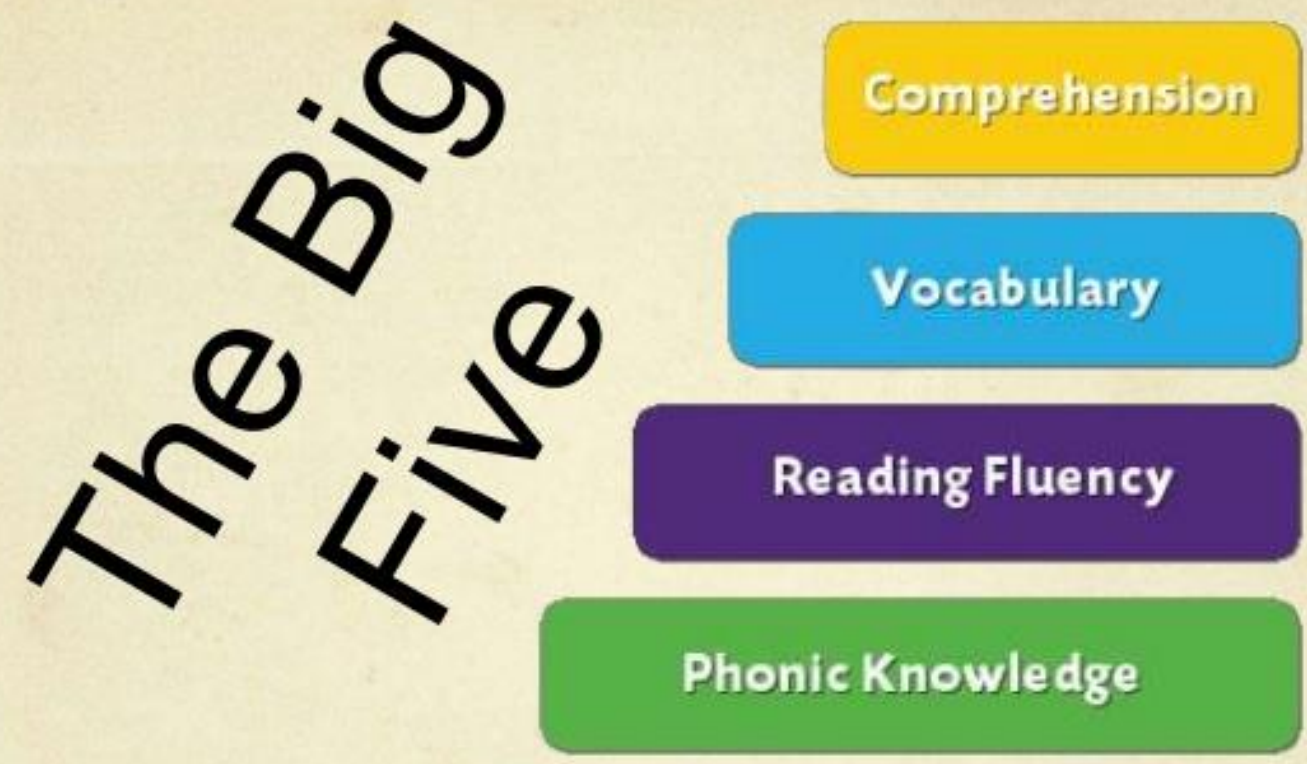

Phonological Awareness

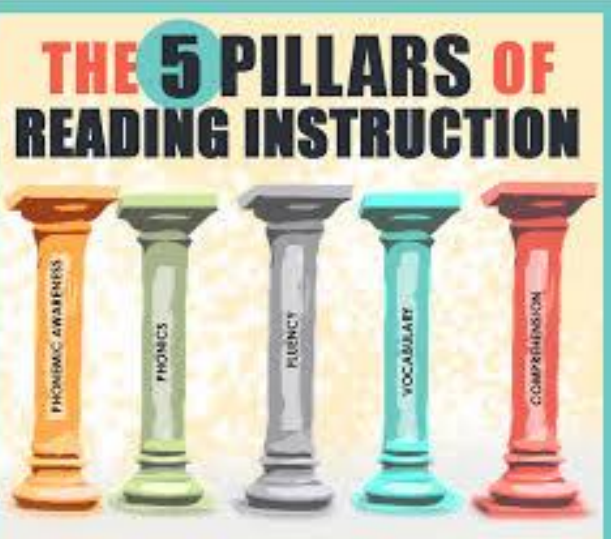




\section{The Five Big Ideas in Beginning Reading}

$$
\text { Conaphenghajon }
$$

\section{Vocabulary}

\section{Reading Fluengy}

Phonis Knowledge

\section{Phonological Awareness}

USA National Reading Panel, 2000 
- 